\title{
VALIDITY AND RELIABILITY OF THE NEPALI VERSION OF THE GENERAL ORAL HEALTH ASSESSMENT INDEX (GOHAI) IN NEPALI POPULATION
}

\author{
Singh $T^{1}$, Ghimire $T R^{1}$
}

\section{Affiliation \\ 1. Lecturer, Department of Dentistry, Devdaha Medical College and Research Institute, Rupandehi, Nepal}

\section{ARTICLE INFO \\ Received : 28 March, 2020 \\ Accepted : 28 August, 2020 \\ Published : 05 October, 2020}

(c) Authors retain copyright and grant the journal right of first publication with the work simultaneously licensed under Creative Commons Attribution License CC - BY 4.0 that allows others to share the work with an acknowledgment of the work's authorship and initial publication in this journal.

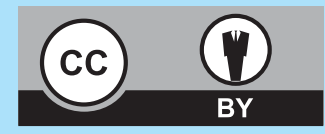

\section{ORA 174}

DOI: https://doi.org/10.3126/bjhs.v5i2.31374

\author{
* Corresponding Author \\ Dr. Tanuja Singh \\ Lecturer \\ Devdaha Medical College and Research Institute \\ Rupandehi, Nepal \\ Email ID: tanujasingh602@gmail.com \\ ORCID ID: https://orcid.org/0000-0002-0294-8052
}

\section{Citation}

Singh T, Ghimire TR. Validity and Reliability of the Nepali Version of The General oral Health Assessment Index (gohai) in Nepali Population. BJHS 2020;5(2)12: 1016-1021.

\section{ABSTRACT}

\section{Introduction}

Oral health problems are more chronic and severe. Various instruments have been developed to measure Oral Health Quality of Life. General Oral Health Assessment Index (GOHAI) is a well-established, frequently used questionnaire for measuring $\mathrm{OHQ}$ oL for geriatric and general population.

\section{Objectives}

The objective of the study is to translate the GOHAI in Nepali and to assess its reliability and validity.

\section{Methodology}

This study was conducted on the patient attending department of Prosthodontics, Kathmandu University School of Medical Sciences from March 2017 to February 2018. The GOHAl questionnaire was translated into Nepali version from English and back translated. Nepali version of GOHAI was pilot tested on 50 adult population to test the comprehensibility of the questionnaire, and then required alterations were done. The final Nepali version of GOHAI was administered to 301 (aged 20-70 years) adults along with the self-informed questionnaire. Clinical examination was done on the same day by a single examiner using World Health Organization (WHO) criteria. Reliability was analyzed using test-retest, cronbach alpha and split half reliability. For validity, discriminant validity and construct validity were calculated.

\section{Results}

Cronbach's alpha was 0.749 , which indicated good overall internal consistency and homogeneity. For test-retest, the spearman's rho correlation coefficient between visits ranged from 0.641-0.952 for all twelve questionnaires indicating strong correlation with $p$-value $<0.001$.

\section{Conclusion}

Nepali version of the GOHAl exhibited acceptable reliability and validity in the people of Kathmandu valley, Nepal. This instrument can be applied to evaluate OHRQoL of different age groups as it was carried out in all the age groups.

\section{KEYWORDS}

Translation, validation, Nepaliversion, GOHAI 


\section{INTRODUCTION}

Dental demands from older patients continue to increase not only due to the growing number of people in this age group but also as a result of various causes of dentition loss. Oral health is one of the vital aspects of life. So, its degradation hinders a person's ability to perform and concentrate on daily activities. Dental problem can degrade the mental, physical, social and psychological well-being of an individual. With increase in age, oral problems are more chronic and severe as they have always been neglected in preference to other health problems ${ }^{1}$.Oral health-related quality of life (OHQoL) has been defined as a self-report specifically pertaining to oral health - capturing the functional, social and psychological impacts of oral disease."2 This definition includes both social and psychological aspects not just the absence of physical diseases. OHQoL needs to be evaluated for the purpose of data collection, policy formulation for health promotion and implementation of the disease prevention program. A number of instruments has been developed in the last two decades to measure OHQoL. ${ }^{3}$ General Oral Health Assessment Index (GOHAI) is a well-established, frequently used questionnaire for measuring OHQoL basically for geriatric population. Self- perceived oral health is an important measure for assessing the priority requirements of this population and implementing actions that result in an improvement in quality of life through the development of various educational and preventive policies for this population. ${ }^{4}$

Most Oral health-related quality of life $(\mathrm{OHQOL})$ instruments ${ }^{5-7}$ that have shown to have adequate validity and reliability based on three main dimensions: physical symptoms, perception of well-being and functional capacity. The General Oral Health Assessment Instrument (GOHAI), developed by Atchison and Dolan, aims to complement clinical measures by paying special attention to problems related to physiological, physical and psychological needs of the patients. ${ }^{8}$ Several studies have shown that the GOHAl is more suitable instrument to measure OHQoL of the elder population in Western cultures than the most frequently used Oral Health Impact Profile (OHIP) ${ }^{9-10}$ The reliability of GOHAl was found to be satisfactory, and all hypotheses designed to assess and check its validity were confirmed in Swedish, ${ }^{11}$ Dutch, ${ }^{12}$ French ${ }^{13}$ and Arabic $^{14}$ studies. To use it in Nepali context first it is essential to carry out a rigorous translation and validation process. ${ }^{15}$ Transferring such indicators from one country to another presents problems at two levels. First, direct translations may present linguistic problems because some words and phrases have no direct translation and questions conceived in the context of one language may not be understood in the same way in the other language. Second, languages exist within social and cultural frameworks that are frequently unique and some questions may therefore become different or meaningless in a different culture and location. ${ }^{7}$ Because of all these reasons it is essential to develop Nepali version of GOHAI and to verify its reliability and validity.
The aim of this study was to translate the GOHAI in Nepali and to assess its reliability and validity in Nepali Context.

\section{MATERIALS AND METHOD}

\section{Study site and population:}

This study was conducted on the patient attending department of Prosthodontics, Kathmandu University School of Medical Sciences from March 2017 to February 2018. The total numbers of 301 people aged $20-70$ years were participated in the study. The sample size was based on the literature available, which mentions that in assessing the reliability and validity of an index or scale, the minimum necessary sample size for coefficient alpha is commonly suggested as $200-400 .^{16-17}$ The common view is that larger sample will produce more accurate result.

\section{Ethical clearance:}

Ethical clearance for the research was approved by the institutional review committee of the Kathmandu University School of Medical Sciences/Dhulikhel Hospital (IRC-KUSMS) (approval number: 26/17). Both written and verbal consent was obtained from the patient who agreed to participate in the study.

\section{Linguistic adaptation:}

The GOHAl questionnaire was translated into Nepali by one language expert and one dentist who were fluent in both Nepali and English. The Nepali version was back translated into English by two other people who were also fluent in both the languages. The original and back translated version was compared to verify, if the questionnaire were translated properly or not by two dentist who are fluent in both the languages. ${ }^{18}$ The final Nepali version of GOHAl was then pilot-tested on a sample of adults $(n=50)$ to make it more understandable.

\section{GOHAI:}

GOHAl was initially designed in United States in 1990 to assess the impact of oral conditions on the quality of life of the elderly population. ${ }^{6}$ It was later termed as General Oral Health Assessment Index (GOHAI) due to its wider application in general population as well. GOHAl consists of 12 questionnaires which assessed oral health in three dimensions; that is, physical functions (eating, speaking, and swallowing), psychosocial functions (worry or concern about oral health, dissatisfaction with appearance, selfconsciousness about oral health, avoidance of social contact because of oral problems), and pain or discomfort (use of medication to relieve pain, oral discomfort).

The questionnaires are worded sometimes in negative and sometimes in positive to compel the respondents to contemplate their answers. The responses were scored on a Likert scale ranging from 1 to 5 (1, always; 2, often; 3 , sometimes; 4 , seldom; 5 , never). The summative score of the index was calculated for each subject, and it ranges from 12 to 60 indicated as additive GOHAI (ADD-GOHAI) where higher ADD-GOHAI score indicates a better OHQoL. A simple count score SC-GOHAI was also calculated for each individual by counting the number of items with response 
"sometimes," "often" or"always" which shows the negative impact of OHQoL (reverse for questions 3,5 and 7 as the questions are worded positively) and ranged from 0 to 12 .

\section{Data Collection:}

All the participants were requested to fill self-informed questionnaire. It comprised of the information regarding subject's age, gender, education, marital and employment status, frequency of tooth brushing, smoking and history of regular visit to dentist. The Nepali version of GOHAI was attached with the history sheet and the author was available all the time to make any queries clear.

Clinical examination was done on the same day by a single examiner when the questionnaire was delivered using World Health Organization (WHO) criteria. $^{19}$

\section{Data Analysis:}

The conventional approach for this study consists of assessment of the reliability of the Nepali version of GOHAI and its construct and discriminant validity.

Reliability was analyzed using test-retest, cronbach alpha and split half reliability. To calculate test-retest reliability, 50 participants repeated the GOHAl questionnaire in the interval of one week. Cronbach's alpha was calculated to assess the degree of internal consistency reliability and uniformity between the items. ${ }^{20}$ Split half reliability was calculated to the internal consistency of the questionnaire.

For the validity test discriminant validity and construct validity were calculated. The discriminant validity was certified by comparing the individuals' item responses and GOHAl scores with their objectively evaluated dental condition. It was hypothesized that there was correlation between the GOHAl score and the oral condition of the subjects. Construct validity was tested by hypothesized OHQoL decreases with more negative responses and increase in age, with participants aged more than 50 years old.

\section{RESULTS}

The total subjects for study were 301 among which 158 $(52.49 \%)$ were male and 143 (47.51\%) were female. The study population age range was between 20 to 70 years among which $42.2 \%$ were above 50 years of age. More than three quarters (77\%) of the 301 participant were married whereas $37.54 \%$ were not employed. Only $26.91 \%$ visited dentist regularly whereas $68.77 \%$ brushed their teeth only once a day. Among the participants $46.51 \%$ had history of smoking on regular basis. The mean add GOHAl was 37.59 $(S D=5.25$; median $=38)$. The mean SC GOHAl was 4.14(SD=2.18; median=4).

For each questionnaire mean, standard deviation and median was calculated (Table: 1 ). The respondent expressed some functional problem. Around $54.15 \%$ (always, often or sometimes) had problem in eating various kinds of food due to their oral condition (Q1) while $48.68 \%$ had problem in chewing hard food (Q2). More than $80 \%$ of participants were able to swallow comfortably (Q3), able to eat without discomfort (Q5), pleased with the look of their teeth (Q7) and were self-conscious of their teeth, gums and dentures (Q10). While $26.91 \%$ were unable to speak clearly, (Q4) and $23.59 \%$ had to limit their contact with people (Q6) due to their oral condition. Less than $50 \%$ had history of using medication to relieve pain (Q8), were uncomfortable eating in front of others (Q11) and sensitive to hot, cold or sweet food (Q12). In addition, 55.15\% of people were worried about their teeth, gum or dentures (Q9) as shown in figure 1.

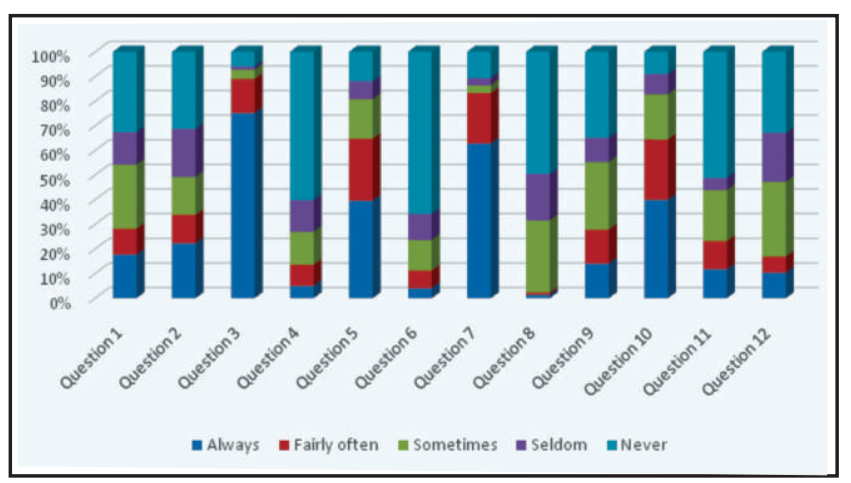

Figure 1: Frequency distribution of the responses for each item $(n=301)$

\section{Reliability:}

Reliability of the Nepali version of GOHAI was assessed with cronbach's alpha was calculated for the data. Cronbach's alpha was found to be 0.749 , which indicated good overall internal consistency and homogeneity between the items. Test re-test reliability was assessed in 50 participants by repeating the same Nepali version of questionnaire in the interval of one week. The test-retest correlation coefficient between visits ranged between 0.641-0.952 (table:1) for all twelve questionnaires indicating strong correlation with $p$-value $<0.001$ which suggest statistically significant. The spearman's rho correlation coefficient for ADD GOHAI is 0.909 with $p$-value $<0.001$ and for SC GOHAl is 0.956 with $p$ value $<0.001$ which illustrate the strong correlation between two successive GOHAI score.

Split half reliability was calculated, the scale was divided into two equal parts (odd number questionnaire one half and even number questionnaire other half) consisting of 6 items each and Cronbach alpha was determined, the correlation between the halves was 0.689 and Spearman brown coefficient was 0.816 . Guttmann split half coefficient was found to be 0.786 .

\begin{tabular}{|c|c|c|c|c|c|c|}
\hline & GOHAI Questionnaires & $\begin{array}{l}\text { Test-retest } \\
\text { correlation }\end{array}$ & $\begin{array}{l}\text { Cronbach's } \\
\text { alpha if item } \\
\text { deleted }\end{array}$ & Mean & Median & SD \\
\hline 1. & $\begin{array}{l}\text { Limit the kind of food } \\
\text { consumed }\end{array}$ & 0.952 & 0.679 & 3.33 & 1.47 & 3 \\
\hline 2. & Trouble biting or chewing & 0.905 & 0.678 & 3.23 & 1.55 & 4 \\
\hline 3. & Able to swallow comfortably & 0.703 & 0.744 & 1.49 & 1.06 & 1 \\
\hline 4. & Unable to speak clearly & 0.852 & 0.719 & 4.15 & 1.23 & 5 \\
\hline 5. & Able to eat without discomfort & 0.685 & 0.726 & 2.27 & 1.36 & 2 \\
\hline 6. & Limit contact with people & 0.889 & 0.722 & 4.27 & 1.17 & 5 \\
\hline 7. & $\begin{array}{l}\text { Pleased with appearance of } \\
\text { teeth }\end{array}$ & 0.843 & 0.720 & 1.78 & 1.30 & 1 \\
\hline 8. & Use medication to relieve pain & 0.641 & 0.768 & 4.14 & 0.96 & 4 \\
\hline 9. & $\begin{array}{l}\text { Worried about teeth, gum } \\
\text { and dentures }\end{array}$ & 0.752 & 0.745 & 3.38 & 1.43 & 3 \\
\hline 10. & $\begin{array}{l}\text { Self-conscious about teeth, } \\
\text { gum and dentures }\end{array}$ & 0.868 & 0.821 & 2.22 & 1.30 & 2 \\
\hline 11. & $\begin{array}{l}\text { Uncomfortable eating in front } \\
\text { of others }\end{array}$ & 0.941 & 0.701 & 3.72 & 1.47 & 5 \\
\hline 12. & $\begin{array}{l}\text { Sensitive to hot, cold or } \\
\text { sweet food }\end{array}$ & 0.804 & 0.713 & 3.58 & 1.29 & 4 \\
\hline
\end{tabular}

GOHAI: General oral health assessment index, SD: Standard deviation

\section{Validity:}

The construct validity (Table:2) was contemplated for age, 
sex, marital status, employment, frequency of brushing, smoking and regular visit to dentist in this population. With increasing age OHRQoL decreased, thus subjects aged more than 50 years of age reporting poorer $\mathrm{OHQ}$ oL and higher number of negative responses. Statistically significant difference was seen in both the mean ADD and SC-GOHAI scores between age groups ( $P<0.01, P<0.01$ respectively). Unemployed and illiterate respondents perceived poorer OHRQoL. Mean ADD-GOHAl and SC-GOHAl score showed a statistically significant difference $(P<0.01, P<0.001)$ respectively. Subjects who had no history of smoking and brushed twice daily reported better OHQOL and statistically significant difference was seen in both the mean ADD and SC-GOHAl scores based on their history of visit $(P<0.01, P=0.01$ respectively for smoking and $\mathrm{P}=0.0002, \mathrm{P}<0.01$ respectively for brushing). Contrary to the hypothesis $\mathrm{OHQ}$ oL was poor in the subjects who visit the dentist regularly and was statistically significant $(P<0.01)$ for both AAD-GOHAI and SCGOHAI. No significant difference was seen in OHRQoL between male and female respondent $(P=0.952$ for ADDGOHAl and $\mathrm{P}=0.463$ for SC-GOHAI).

\begin{tabular}{|c|c|c|c|c|c|}
\hline Variable & $n(\%)$ & $\begin{array}{c}\text { Mean } \\
\text { ADD-GOHAI (SD) }\end{array}$ & $\begin{array}{l}\text { Statistical test } \\
P\end{array}$ & $\begin{array}{c}\text { Mean } \\
\text { SC-GOHAI (SD) }\end{array}$ & $\begin{array}{c}\text { Statistical test } \\
\text { P }\end{array}$ \\
\hline \multicolumn{6}{|l|}{ Age } \\
\hline$\leq 30$ & $100(33.2)$ & $39.6(4.1)$ & \multirow[t]{2}{*}{ ANOVA } & $3.1(1.8)$ & \multirow[t]{2}{*}{ ANOVA } \\
\hline $31-50$ & $74(24.6)$ & $38.5(6.1)$ & & $3.6(2.0)$ & \\
\hline$>50$ & $127(42.2)$ & $35.5(4.8)$ & $P<0.01$ & $5.4(1.9)$ & $P<0.01$ \\
\hline $\begin{array}{c}\text { Gender } \\
\text { Male }\end{array}$ & $158(52.5)$ & $37.6(4.2)$ & T-test & $4.2(2.2)$ & T-test \\
\hline Female & $143(47.5)$ & $37.5(4.1)$ & $\mathrm{P}=0.952$ & $4.1(2.1)$ & $P=0.463$ \\
\hline \multicolumn{6}{|l|}{ Education } \\
\hline Literate & $235(78)$ & $38.7(4.7)$ & \multirow[t]{2}{*}{ T-test } & $3.7(2.0)$ & \multirow[t]{2}{*}{ T-test } \\
\hline Illiterate & $66(22)$ & $33.4(4.9)$ & & $5.9(1.7)$ & \\
\hline & & & $P<0.01$ & & $\mathrm{P}<0.01$ \\
\hline \multicolumn{4}{|l|}{ Marital status } & $4.5(2.2)$ & T-test \\
\hline Unmarried & $68(22.6)$ & $39.54(4.4)$ & $P=0.0001$ & $2.9(1.8)$ & $\mathrm{P}<0.01$ \\
\hline \multicolumn{6}{|l|}{ Employment } \\
\hline Employed & $188(62.5)$ & $38.9(4.4)$ & T-test & $3.6(2.1)$ & T-test \\
\hline Unemployed & $113(37.5)$ & 35.4 (5.9) & $P<0.01$ & $5.0(2.0)$ & $P<0.01$ \\
\hline $\begin{array}{l}\text { Frequency of brushing } \\
\text { Once }\end{array}$ & $207(68.8)$ & $36.9(5.4)$ & -test & $4.5(2.1)$ & T-test \\
\hline Twice & $94(31.2)$ & $39.1(4.5)$ & $P=0.0002$ & $3.4(2.0)$ & $P<0.01$ \\
\hline $\begin{array}{l}\text { Smoking } \\
\text { Yes }\end{array}$ & $140(46.5)$ & $36.3(5.5)$ & T-test & $4.7(2.2)$ & T-test \\
\hline $\begin{array}{l}\text { Yes } \\
\text { No }\end{array}$ & $161(53.5)$ & $38.7(4.8)$ & $P<0.01$ & $3.7(2.0)$ & $P<0.01$ \\
\hline $\begin{array}{l}\text { Regular visit to dentist } \\
\text { No }\end{array}$ & $81(26.91)$ & $39.6(4.9)$ & T-test & $3.4(1.9)$ & T-test \\
\hline Yes & $220(73.09)$ & $36.8(5.2)$ & $P<0.01$ & $4.4(2.2)$ & $P<0.01$ \\
\hline
\end{tabular}

Discriminant validity (Table 3 ) analysis showed that lower mean ADD-GOHAl score was seen in patients with lesser number of teeth present, greater number of missing teeth, decayed teeth and gingival recession whereas there is not much difference in mean ADD-GOHAl restored and traumatized teeth. Mean ADD-GOHAI is higher for the crowned teeth. Statistically significant difference was seen in the mean GOHAI scores (both ADD-GOHAI, SC-GOHAI) for clinical parameters like number of teeth present, number of missing teeth, gingival recession and crowned teeth $(P<$ 0.01 to 0.001$)$. Whereas for number of decayed teeth, restored teeth and traumatized teeth no statistically significant difference was seen in both ADD-GOHAI and SCGOHAI ( $P=0.116$ to $0.606, P=0.095$ to 0.207 respectively).

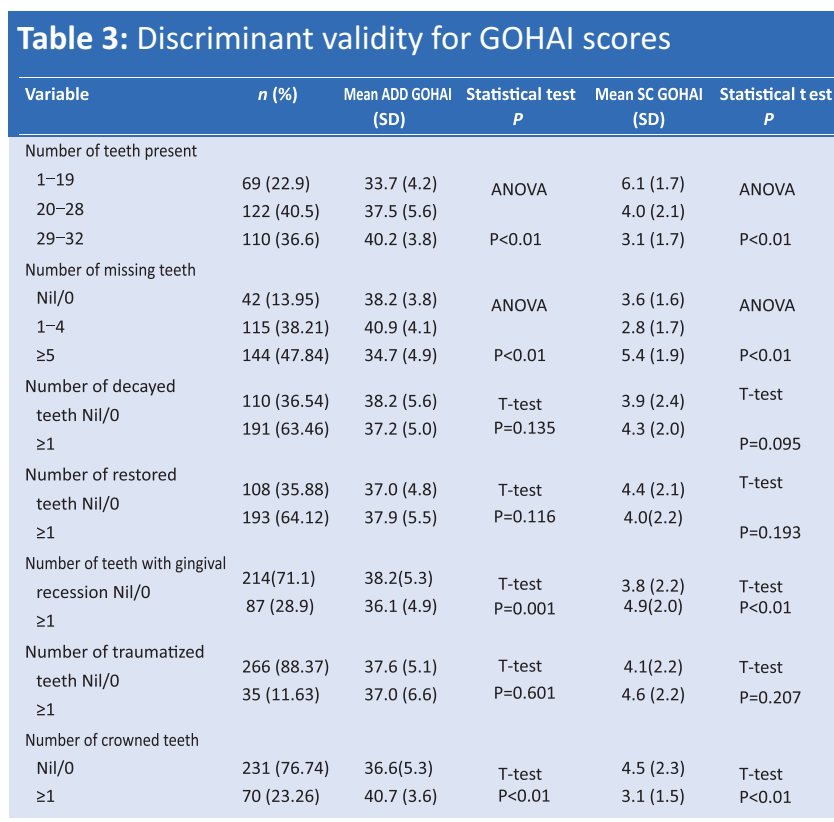

\section{DISCUSSION}

This study assessed the validity and reliability of the Nepali version of the GOHAI. The original GOHAI was validated in a well-educated, older Americans population. Though the GOHAl has been also validated for younger and for less educated population, ${ }^{21,22}$ It remains important that reliability and validity problems related to differences in language or culture are ruled out to use in that population. Thus, the GOHAl should be tested in diverse populations in terms of language, culture and geography.

In this study, the first step consisted of translation process. Translation and back-translation were carried to ensure the precision and accountability of the questions, which led Nepali version of GOHAl with satisfactory psychometric properties. No significant difference in the mean GOHAI scores was observed on assessment of social and demographic parameters like age and gender.

The current study established the reliability and validity of Nepali version of GOHAI. The translated Nepali version was consistent, irrespective of the educational status of the study population. The Cronbach alpha for internal consistency was found to be 0.749 which showed the good internal consistency and similar to that of Hindi 0.79, Spanish 0.77, Persian 0.78, Portuguese 0.76 and Malay $0.79 .^{23-27}$ This value did not become undoubtedly larger by excluding any of the questions, except question 10 (Self-conscious of teeth, gums or dentures), which showed less internal consistency, suggesting poor compatibility with other GOHAl questions and exclusion of which will increase the value of Cronbach alpha (table 1).

Socioeconomic data suggest $37.5 \%$ are unemployed. Selfrating of oral health was particularly poor and perception of dental care needs was high, indicating a substantial negative impact of oral conditions. This is in accordance with previous findings showing that populations with lower socioeconomic 
status experienced a greater negative impact of oral conditions on functioning and well-being. ${ }^{28}$ The perception of oral health and the level of acceptance of oral conditions may vary according to the country and the socioeconomic status, irrespective of the objective dental status. ${ }^{14,29}$

Test-retest Spearman rho correlations between visits were very strong $(P<0.001)$ indicating high reliability and stability of Nepali version of GOHAl questionnaire similar to that of Tamil version. ${ }^{30}$ The mean for the individual question ranges from 1.49 to 4.27 , with minimum impact on unable to speak clearly and limit the contact with people. The maximum impact is seen in able to swallow comfortably, which was also seen in the longitudinal survey conducted by Dolan. ${ }^{31}$ This question was originally developed for the people with xerostomia which is more common in older adults and seems less relevant to younger individuals, ${ }^{21}$ thus inclusion of this question in GOHAl should be reconsidered.

Discriminant and construct validity were established. This study shows good correlation between GOHAl score, personal information and clinical parameters but the subjects with the crowned teeth had better OHQoL than the subject who did not have crown in their oral cavity. Similarly subjects with traumatized teeth and non-traumatized teeth had similar responses indicating irrespective of clinical condition, self-perception of one's own health play vital role in seeking professional advice. Thus the Nepali version of GOHAl can be used in general Nepalese population in all age group to assess the OHQol.

During the manuscript preparation of this study, another similar study done in Nepali geriatric population of eastern Nepal shows acceptable validity and reliability when used for geriatric people residing in old age homes. ${ }^{32}$

\section{CONCLUSION}

The Nepali version of the GOHAl exhibited acceptable reliability and validity in the people of Kathmandu valley, Nepal.

\section{RECOMMENDATION}

This instrument can be applied to evaluate OHRQoL of different age groups as it was carried out in all the age groups to formulate the oral health related policies in Nepal.

\section{LIMITATION OF STUDY}

Hospital based study at clinical setting may restrict the population level generalization.

\section{ACKNOWLEDGEMENT}

I would like to acknowledge Dr Binam Sapkota, Dr Tanoj Bahadur Singh and Dr Vinay Marla for their support and valuable suggestion for this research. I express my sincere gratitude towards IRC-KUSMS and all the participants of this study.

\section{CONFLICTS OF INTEREST}

The author(s) declare(s) that there was no conflict of interest.

\section{FUNDING STATEMENT}

All the financial expenses for this research was borne by authors themselves. Authors have not received any financial grant from external sources.

\section{REFERENCES}

1. Rouxel P, Tsakos G, Chandola T, Watt RG. Oral health-a neglected aspect of subjective well-being in later life. The Journals of Gerontology: Series B. 2016 Mar 12;73(3):382-6. PMID: 26970523

2. Gift HC, Atchison KA. Oral health, health, and health-related quality of life. Med Care 1995; 33(11 Suppl):57S-77S. PMID: 7475433

3. Sischo L, Broder HL. Oral health-related quality of life: what, why, how, and future implications. J Dent Res. 2011;90(11):1264-70. PMID: 21422477

4. Mesas $A E$, De Andrade SM, Cabrera MA. Factors associated with negative self-perception of oral health among elderly people in a Brazilian community. Gerodontology. 2008 Mar;25(1):49-56. PMID: 18194333

5. Slade GD, Spencer AJ. Development and evaluation of the oral health impact profile. Community dental health. 1994 Mar;11(1):3-11. PMID: 8193981

6. Atchison KA, Dolan TA. Development of the geriatric oral health assessment index. Journal of dental education. 1990 Nov 1;54(11):680-7. PMID: 2229624

7. McGrath C, Bedi R. Measuring the Impact of Oral Health on Quality of Life in Britain Using OHQoL-UKC. Journal of public health dentistry. 2003 Jun;63(2):73-7. PMID: 12816136

8. Gil-Montoya JA, Subirá C, Ramón JM, González-Moles MA. Oral health-related quality of life and nutritional status. Journal of public health dentistry. 2008 Mar;68(2):88-93. PMID: 18248335

9. Locker D, Matear D, Stephens M, Lawrence H, Payne B. Comparison of the GOHAI and OHIP-14 as measures of the oral health-related quality of life of the elderly. Community dentistry and oral epidemiology. 2001 Oct;29(5):373-81. PMID: 11553110

10. Hassel AJ, Rolko C, Koke U, Leisen J, Rammelsberg P. A German version of the GOHAI. Community dentistry and oral epidemiology. 2008 Feb;36(1):34-42. PMID: 18205638

11. Hägglin C, Berggren U, Lundgren J. A Swedish version of the GOHAI index. Psychometric properties and validation. Swedish dental journal. 2005;29(3):113-24. PMID: 16255355

12. Niesten D, Witter D, Bronkhorst E, Creugers N. Validation of a Dutch version of the Geriatric Oral Health Assessment Index (GOHAI-NL) in care-dependent and care-independent older people. BMC geriatrics. 2016 Dec;16(1):53. PMID: 26928080

13. Tubert-Jeannin S, Riordan PJ, Morel-Papernot A, Porcheray S, Saby-Collet $S$. Validation of an oral health quality of life index (GOHAI) in France. Community dentistry and oral epidemiology. 2003 Aug;31(4):275-84. PMID: 12846850

14. Daradkeh S, Khader YS. Translation and validation of the Arabic version of the Geriatric Oral Health Assessment Index (GOHAI). Journal of oral science. 2008;50(4):453-9. PMID: 19106474

15. Murariu A, Hanganu C, Bobu L. Evaluation of the reliability of the geriatric oral health assessment index (GOHAI) in institutionalised elderly in Romania: a pilot study. OHDMBSC. 2010 Mar;9(1):11-5. 
16. Frost MH, Reeve BB, Liepa AM, Stauffer JW, Hays RD, Mayo/FDA Patient-Reported Outcomes Consensus Meeting Group. What is sufficient evidence for the reliability and validity of patient-reported outcome measures?. Value in Health. 2007 Nov;10:S94-105. PMID: 17995479

17. Charter RA. Sample size requirements for precise estimates of reliability, generalizability, and validity coefficients. Journal of Clinical and Experimental Neuropsychology. 1999 Aug 1;21(4):559-66. PMID: 10550813

18. Guillemin F, Bombardier C, Beaton D. Cross-cultural adaptation of health-related quality of life measures: literature review and proposed guidelines. Journal of clinical epidemiology. $1993 \mathrm{Dec}$ 1;46(12):1417-32. PMID: 8263569

19. World Health Organization. Oral Health Surveys, Indices and Methods for Measurement of Dental Diseases. 4th ed. Geneva: World Health Organization (WHO); 1997. p. 21-51.

20. Cronbach LJ. Coefficient alpha and the internal structure of tests. psychometrika. 1951 Sep 1;16(3):297-334. DOI: 10.100/BF02310555

21. Atchison KA, Der-Martirosian C, Gift HC. Components of self-reported oral health and general health in racial and ethnic groups. Journal of public health dentistry. 1998 Dec;58(4):301-8. DOI: 10.1111/j.1752-7325.1998.tb03013.x

22. Tubert-Jeannin S, Riordan PJ, Morel-Papernot A, Porcheray S, Saby-Collet S. Validation of an oral health quality of life index (GOHAI) in France. Community dentistry and oral epidemiology. 2003 Aug;31(4):275-84. PMID: 12846850

23. Sánchez-García S, Heredia-Ponce E, Juárez-Cedillo T, GallegosCarrillo K, Espinel-Bermúdez C, De La Fuente-Hernández J, García-Peña C. Psychometric properties of the General Oral Health Assessment Index (GOHAl) and dental status of an elderly Mexican population. Journal of public health dentistry. 2010 Sep;70(4):300-7. PMID: 20663049
24. Motallebnejad M, Mottaghi K, Mehdizadeh S, Alaeddini F, Bijani A. Reliability and validity of the Persian version of the general oral health assessment index (GOHAI). Caspian Journal of Dental Research. 2013 Mar 10;2(1):8-17. DOI: 10.22088/cjdr.2.1.8

25. Carvalho C, Manso AC, Escoval A, Salvado F, Nunes C. Translation and validation of the Portuguese version of the geriatric oral health assessment index (GOHAI). Rev Port Public Health. 2013;31(2):166 72.DOI: 10.1016/j.rpsp.2013.10.002

26. Othman WN, Muttalib KA, Bakri R, Doss JG, Jaafar N, Salleh NC, Chen S. Validation of the geriatric oral health assessment index (GOHAI) in the Malay language. Journal of public health dentistry. 2006 Sep;66(3):199-204. PMID: 16913247

27. Mathur VP, Jain V, Pillai RS, Kalra S. Translation and validation of Hindi version of Geriatric Oral Health Assessment Index. Gerodontology. 2016 Mar;33(1):89-96. PMID: 24325659

28. Kressin NR, Atchison KA, Miller DR. Comparing the impact of oral disease in two populations of older adults: application of the geriatric oral health assessment index. Journal of public health dentistry. 1997 Dec;57(4):224-32. DOI: 10.1111/j.1752-7325.1997. tb02979.x

29. Wong MC, Liu JK, Lo EC. Translation and validation of the Chinese version of GOHAI. Journal of public health dentistry. 2002 Jun;62(2):78-83. PMID: 11989210

30. Appukuttan DP, Vinayagavel M, Balasundaram A, Damodaran LK, Shivaraman P, Gunasshegaran K. Linguistic Adaptation and Psychometric Properties of Tamil Version of General Oral Health Assessment Index Tml. Annals of medical and health sciences research. 2015;5(6):413-22. PMID: 27057380

31. Dolan TA. The sensitivity of the Geriatric Oral Health Assessment Index to dental care. Journal of dental education. 1997 Jan 1;61(1):37-46. PMID: 9024341

32. Agrawal SK, Shrestha A, Bhagat T. Translation and validation of the Nepalese version of the Geriatric Oral Health Assessment Index. Gerodontology. 2019 Mar;36(1):30-5. DOI: 10.1111/ger.12373 